\title{
Profiles of Childhood Psychological Abuse and Neglect among Chinese College Students and Their Problematic Online Behaviors \\ Short Title: Profiles of Childhood Psychological Abuse and Neglect
}

\author{
Baojuan Ye ${ }^{1}$, Nannan Fan ${ }^{1}$, Hohjin $\mathrm{Im}^{2}$, Mingfan Liu ${ }^{1}$, Xinqiang Wang ${ }^{1} \&$ Qiang Yang ${ }^{1}$ \\ ${ }^{1}$ Jiangxi Normal University, ${ }^{2}$ University of California, Irvine
}

Baojuan Ye, Center of Mental Health Education and Research, School of Psychology, Jiangxi Normal University, 99 Ziyang Avenue, Nanchang 330022, China, Phone (86-0791-88120173), email (yebaojuan0806@163.com). Her major research focuses on college students' development.

Nannan Fan, Center of Mental Health Education and Research, School of Psychology, Jiangxi Normal University, 99 Ziyang Avenue, Nanchang 330022, China, Phone (86-0791-88120173), email (15716596919@163.com). Her major research focuses on college students' development.

Hohjin Im, Department of Psychological Science, University of California, Irvine, email (hohjini@uci.edu). He is a social psychology doctoral student. His research focuses on ingroup favoritism. He incorporates perspectives of cultural psychology into his work, examining how those of different cultural backgrounds perceive and rationalize behavior in ethics. *Corresponding author.

Mingfan Liu, Center of Mental Health Education and Research, School of Psychology, Jiangxi Normal University, 99 Ziyang Avenue, Nanchang 330022, China, Phone (86-791-88123522), email (lmfxub@sina.com). Her major research interests include adolescent problem behaviors, and adolescents' social-emotional development.

Xinqiang Wang, Center of Mental Health Education and Research, School of Psychology, Jiangxi Normal University, 99 Ziyang Avenue, Nanchang 330022, China, Phone (86-791-88120173), email (xinqiangw101@163.com). His major research interests include adolescent problem behaviors, and adolescents' meaning in life.

Qiang Yang, School of Education, Jiangxi Normal University, 99 Ziyang Avenue, Nanchang 330022, China, Phone (86-791-88120280), email (davidyang12345@163.com). His major research interest is adolescents' development.

Note: This is an unpublished preprint that has not yet undergone peer-review. This preprint is a working paper and thus is subject to changes with ongoing analyses, updates, and reconceptualization of related variables. This preprint is shared to facilitate quick dissemination of results. Reported findings and interpretations are not final and should not be used to guide policy or practices. 


\begin{abstract}
Background: Studies have shown that multiple forms of abuse may co-occur, resulting in specific abuse typologies. However, there is little understanding of complex interrelations of the different psychological abuse subgroups and internet game addiction and cyber-bullying.

Objective: The objective of this study was to identify latent profiles of childhood psychological abuse and neglect among Chinese college students. Further, this study sought to examine the demographic characteristics of these profiles and the correlations between the profiles and problematic internet behaviors.
\end{abstract}

Methods: Latent profile analysis was undertaken to examine patterns among abuse and neglect characteristics. One-way multivariate analysis of variance was used to examine the differences among profiles across six dimensions of psychological abuse and neglect. Multinomial logistic regression was then used to further examine how these profiles differed in demographic characteristics. Finally, Wald chi-square test was used to examine differences across profiles on online aggressive behavior and online gaming addiction.

Results: Five latent profiles were identified: (1) Low Abuse and Neglect, (2) More Bark Than Bite, (3) Moderate Abuse and Neglect, (4) Traditional High Abuse and Neglect, and (5) High Abuse and Neglect. These profiles varied significantly across assessed domains of demographic characteristics, internet game addiction and cyber-bullying. Results indicated differential needs for effective interventions to address childhood psychological abuse and neglect.

Conclusions: College students' online game addiction and online bullying behavior were closely related to childhood psychological abuse and neglect. In addition to problematic online behaviors, we conclude with discussion of the demographic characteristics of different potential categories. These findings have both practical and empirical significance for understanding and classifying experiences of psychological abuse and neglect.

Abstract Word Count: 264

Keywords: Psychological abuse and neglect, Internet game addiction, Cyber-bullying, Latent profile analysis 


\section{Profiles of Childhood Psychological Abuse and Neglect among Chinese College Students and Their Problematic Online Behaviors}

\section{Introduction}

Childhood psychological maltreatment is a global problem associated with a myriad of adverse consequences (Shaw \& De Jong, 2012) and presents itself as a universal issue in all forms of child maltreatment experiences (Arslan, 2017; Jellen, Mccarroll, \& Thayer, 2001; Miller-Perrin \& Perrin, 2007). Encompassing emotional maltreatment and psychological aggression, psychological maltreatment is recognized as an essential component of child abuse (Fang \& Wang, 2020). While childhood psychological maltreatment may take on different forms, it is primarily characterized as a repeated pattern of behaviors that convey to children and adolescent minors a sense of worthlessness, unwantedness, lack of love, and menial valuation no more than to meet the needs of others (Miller-Perrin, Perrin, \& Kocur, 2009). Despite its importance and relevance to proper childhood development, however, childhood psychological maltreatment has received scant attention compared to its counterpart in physical abuse (Feiring \& Zielinski, 2011; Fu et al., 2018).

Childhood psychological maltreatment often shakes the foundation of one's trajectory of proper development into their young adulthood. Compared with physical abuse, childhood psychological maltreatment is more likely cause subtler, long-lasting damage to children's cognitive, emotional, and behavioral development (Arslan, 2017; Deng, Pan, Tang, Yuan, \& Xiao, 2007; Miller-Perrin \& Perrin, 2007; Miller-Perrin et al., 2009; Paul \& Eckenrode, 2015). Indeed, Miller-Perrin and colleagues (2007; 2009) found further evidence of the negative effects of childhood psychological maltreatment on college students' psychological outcomes (e.g., 
anxiety, depression, and hostility). As a result, psychological outcomes have been proposed to be more destructive than the negative consequences of physical abuse (Claussen \& Crittenden, 1991; Crittenden, Claussen, \& Sugarman, 1994; Hart, Binggeli, \& Brassard, 1998).

While scholars have worked to examine childhood abuse and its consequences, recent empirical evidence suggests that different forms of abuse are likely to overlap and interact (Debowska \& Boduszek, 2017), creating specific combinations which, compared to subtypes of abuse alone, may be uniquely related to particular psychosocial consequences (Berzenski \& Yates, 2011; Green et al., 2010; Hamby \& Grych, 2013; Wolfe \& McGee, 1994). In other words, studies on childhood abuse and its consequences have traditionally taken a more variablecentered modeling approach, whereby the associations between study variables are given focus. These traditional approaches, however, do not allow for controlling of co-occurrences, or lack thereof, between various types of psychological abuse and neglect (Green et al., 2010; Scott, Varghese, \& McGrath, 2010). More reliable information concerning the patterns of concomitance of psychological abuse and neglect types may be obtained using person-oriented techniques, such as latent profile analysis (LPA) that allow for the examination of ways in which numerous characteristics are configured within the individuals (Elhai, Rozgonjuk, Yildirim, Alghraibeh, \& Alafnan, 2019; Maddison, Golay, \& Muncer, 2018).

In recent years, some researchers have taken this approach to examine the categorical nature of patterns of childhood abuse and neglect (Cecil, Viding, Barker, Guiney, \& McCrory, 2014; Petrenko, Friend, Garrido, Taussig, \& Culhane, 2016). However, only one research study, to the best of our knowledge, has been published on psychological abuse and neglect of junior high school students in China using similar person-oriented techniques (Liu, Ju, \& Liu, 2019). The importance of using person-oriented techniques also partly lie in our knowledge that 
categories of abuse and neglect are likely to vary by different age groups (Debowska, Willmott, Boduszek, \& Jones, 2017) and possibly by culture. Thus, an exploratory analysis may benefit the field by examining the characteristics of these categories with respect to the sample's developmental stage and social ecological environment. Hence, this study utilized LPA to more accurately explore the patterns of childhood psychological abuse and neglect among Chinese college students.

An additional goal for this study was to examine the behavioral consequences of childhood psychological abuse and neglect. Behavioral effects of psychological abuse have been evidenced to manifest beyond one's childhood (Norman et al, 2014). While many studies have been conducted investigating real-world problematic behaviors related to childhood abuse and neglect, little attention has been given to online behaviors. This is likely to be important as online social interactions are becoming more and more common among youth and have dominated the current social ecology as many societies have transitioned to online interactions in lieu of inperson activities amidst the COVID-19 outbreak. Notably, online game addiction and cyberbullying are two commonly cited problematic online behaviors among the youth today. Recent studies have documented that the severity of these problematic behaviors is tied to childhood psychological abuse and neglect (Katz, Lemish, Cohen, \& Arden, 2019; Livazovic \& Ham, 2019). However, given the recency of this relation, examinations of these complex interrelations regarding different psychological abuse subgroups and internet game addiction and cyberbullying remain scant and warrant further study. Empirically identifying patterns of different forms of psychological abuse and neglect may help to facilitate a more precise estimation of the prevalence of adverse childhood experiences among Chinese college students and understand its negative impact on problematic online behavior. Such findings, in turn, may aid the future 
formulation of interventions and policies toward addressing the well-being of children and adolescents.

\subsection{The Present Study}

This study had three objectives: (1) identifying profiles of psychological abuse and neglect, (2) exploring demographic characteristic of difference profiles of psychological abuse neglect, and (3) exploring the relations between these different categories and online game addiction and cyber-bullying. Prior research has shown consistent set of latent profiles characterized by multiple types of abuse experiences (Debowska et al., 2017). Similarly, we expected to find qualitatively different profiles in type and severity of psychological abuse and neglect, with the largest group comprised of individuals with low severity across all types of psychological abuse and neglect, serving as the comparative reference group for normative development. Further, we expected individuals belonging to psychological abuse and neglect group to present more complex psychological situations. Profiles marked by high qualities of

psychological abuse and neglect were expected to exhibit greater problematic internet behaviors than the comparison normative profile marked by low childhood psychological abuse and neglect.

\section{Methods}

\subsection{Participants}

After obtaining the college's approval and participants' consent, the research team distributed questionnaires to 1,347 college students (785 females, $58.3 \%$ ) in a central province of China where $327(24.35 \%)$ were first years, 606 (45.01\%) were second years, 243 (18.09\%) were third years, and $171(12.55 \%)$ were fourth years or higher. The mean age of participants was $20.12(S D=1.35)$. Students anonymously completed the survey designed to collect 
demographic variables, child abuse and neglect, and lastly, internet and computer game addiction as well as cyber-bullying.

\subsection{Measures}

2.2.1 Child abuse and neglect questionnaire (CPANS). Child Psychological Abuse and Neglect Scale (CPANS), a 31-item questionnaire, was developed for adolescents in the Chinese population, and its psychometric properties were also examined in the Chinese adolescent population (Deng et al., 2007; Pan, Deng, Guan, \& Luo, 2010). Many previous studies have used this scale with good reliability and validity in Chinese samples (e.g., Jin et al., 2017; Liu et al., 2018; Sun et al., 2017; Zhou et al., 2019). This scale include six dimensions: (1) threat (4 item, e.g., "Parents threatened me with words such as: lock you up; kick you out; forbid you to eat; etc."); (2) derogation (4 item, e.g., "Parents list my shortcomings in front of others"); (3) intervention (6 item, e.g., "Parents peek at my diary"); (4) physical neglect ( 4 item e.g., "Parents don't forbid me to drink; Parents don't care if what I eat is nutritious; etc."); (5) education neglect (7 item e.g., "Parents don't care about the changes in my grades; Parents don't communicate with me about the situation at school; etc."); (6) emotional neglect (6 item e.g., "When I am sad or afraid of parents don't comfort me; Parents don't like me in a certain way; etc.”). Each item is scored from 0 (never) to 4 (always). Responses to all items were averaged, with higher scores representing higher levels of childhood psychological maltreatment. In this study, Cronbach's $\alpha$ was 0.91 and model fit indices $(\mathrm{GFI}=0.917, \mathrm{AGFI}=0.896, \mathrm{CFI}=0.899, \mathrm{RMSEA}=0.059)$ indicated good fit.

2.2.2 Online Aggressive Behavior Scale (OABS). Online Aggressive Behavior was measured by the Online Aggressive Behavior Scale (Zhao, Gao, 2012), which consisted of 16 items (e.g., "I say some bad things about someone on the Internet with other friends") and 
assesses Instrumental and Reactive aggression. Each item was rated on a 4-point scale $(0=$ never to 4 = always), with higher total scores indicating higher levels of online aggressive behavior.

The Chinese version of Online Aggressive Behavior scale has been demonstrated to be a reliable and valid measurement in assessing online aggressive behavior among Chinese samples (Jin et al., 2018; Lu et al., 2019). In the present study, Cronbach's $\alpha$ for this scale was 0.95 and model fit indices $(\mathrm{CFI}=0.920, \mathrm{NFI}=0.93, \mathrm{IFI}=0.987, \mathrm{RMSEA}=0.040)$ indicated good fit.

2.2.3 Online Gaming Addiction Scale (OGAS). Online gaming addiction was measured with the Online Gaming Addiction Scale (Zhou \& Yang, 2006), which assessed 8 items (e.g., "My spare time is basically spent on playing games"). Each item was rated on a 5-point scale (0 $=$ Strongly Disagree to $4=$ Totally Agree), with higher total scores indicating higher levels of Gaming Addiction tendency. The Chinese version of Online Gaming Addiction Scale has been demonstrated to be a reliable and valid measurement in assessing online aggressive behavior among the Chinese (Wei, Zhou, Tian, \& Bao, 2012). In the present study, Cronbach's alpha for this scale was 0.95 and model fit indices $(\mathrm{CFI}=0.980, \mathrm{NFI}=0.970, \mathrm{IFI}=0.980, \mathrm{RMSEA}=$ 0.070) indicated good fit.

2.2.4 Demographic Characteristics. Participants were also asked to report several demographic characteristics including their biological sex, whether they are a single child, their home address environment (city vs. rural), their parents' education attainment (Less than Junior High School, Junior High School, High School, and Graduate Degree and Above), and family income ( $¥ 4,000$ or below, $¥ 4,000-6,000, ¥ 6,000-8,000, ¥ 8,000-10,000$, or $¥ 10,000$ or above).

\subsection{Procedure}

This study was approved by the Ethics Committee of the School of Psychology at the first author's institution. All participants provided informed consent in participating in this study 
and data were collected anonymously. Researchers emphasized the authenticity, independence, and integrity of all answers to the participants. As an incentive for their participation, participants received a small gift (worth approximately $¥ 5$ ) upon completion of the questionnaire.

\subsection{Analytical approach}

First, to establish a statistically and conceptually valid set of profiles, an LPA was run with Mplus 7 using scores from the child abuse and neglect questionnaire. Maximum Likelihood estimation was used with robust standard errors (MLR) for the LPA, analyzing two through seven-profile models following prior studies examining child abuse symptoms (e.g., Franz, \& Annabel, 2015). Various steps and procedures were taken to determine the optimal profile solution, including examining the profile that yielded the lowest Bayesian Information Criterion (BIC) and sample-size adjusted BIC values (SSABIC), using significant Lo-Mendell-Rubin Adjusted Likelihood Ratio Test value (LMR), referring to significant Bootstrapped Likelihood Ratio Test (BLRT) $p$-values, good entropy values (quality of profileification), parsimony, and interpretative meaning (DiStefano \& Kamphaus, 2006; Nylund, Asparouhov, \& Muthén, 2007; Nylund, Bellmore, Nishina, \& Graham, 2007).

Secondly, one-way multivariate analysis of variance (MANOVA) was used to examine the differences among profiles across six dimensions of psychological abuse and neglect. Thirdly, multinomial logistic regression was used to identify factors that predicted membership within these profiles. After identifying the best-fitting profile solution, we tested differences across profiles on the online aggressive behavior, online gaming addiction with Wald chi-square test. Posterior profile probabilities were imported into SPSS and Mplus 7.0 for these analyses.

\section{Results}

\subsection{Preliminary analyses}


Table 1. Means, standard deviations, and correlations of the main study variables.

\begin{tabular}{lccccc}
\hline \multicolumn{1}{c}{ Variables } & $\boldsymbol{M}$ & $\boldsymbol{S D}$ & $\mathbf{1}$ & $\mathbf{2}$ & $\mathbf{3}$ \\
\hline 1.Abuse and Neglect & 1.94 & 0.60 & - & & \\
2.Internet Game Addiction & 2.10 & 0.91 & $0.36^{* * *}$ & - & \\
3.Cyber-bullying & 1.24 & 0.45 & $0.35^{* * *}$ & $0.31^{\text {*** }}$ & - \\
\hline
\end{tabular}

Note: $N=1347 ;{ }^{* * *} p<0.001$

Table 1 shows the correlations between all the measures and the child abuse, together with the descriptive statistics. Psychological abuse and neglect were positively related to online aggressive behavior $(r=0.35, p<0.001)$ and online gaming addiction $(r=0.36, p<0.001)$.

\subsection{Latent profile}

Table 2. Fit Indices for the latent profile analysis.

\begin{tabular}{lcccccc}
\hline Model & AIC & BIC & aAIC & Entropy & LMR-LTRT(P) & BLRT(P) \\
\hline 2-Cluster & 17141.872 & 17241.688 & 17181.332 & 0.883 & 0.0000 & $0.0000<0.001$ \\
3-Cluster & 16279.388 & 16415.978 & 16415.385 & 0.822 & 0.0001 & $0.0000<0.001$ \\
4-Cluster & 16040.410 & 16213.774 & 16108.945 & 0.869 & 0.7885 & $0.0000<0.001$ \\
5-Cluster & $\mathbf{1 3 0 1 4 . 9 2 3}$ & $\mathbf{1 3 2 2 5 . 0 6 2}$ & $\mathbf{1 3 0 9 7 . 9 9 6}$ & $\mathbf{0 . 8 9 4}$ & $\mathbf{0 . 0 2 4 8}$ & $\mathbf{0 . 0 0 0 0}<\mathbf{0 . 0 0 1}$ \\
6-Cluster & 12573.438 & 12818.103 & 12668.804 & 0.919 & 0.0055 & $0.0000<0.001$ \\
7-Cluster & 12106.039 & 12387.143 & 12215.608 & 0.880 & \#\#\# & \#\#\# \\
\hline
\end{tabular}

Note: $N=1347$; Boldface font indicates the selected model; "\#\#\#” indicates that the model did not converge.

Table 2 shows the fit indices for 2 to 7 profile models. While the 6-profile model yielded better fit indices than the 5-profile model, the 6th profile did not introduce a conceptually substantive addition to the 5-profile model. Based on recommended guidelines for model identification and interpretability (i.e., qualitatively different profiles) (DiStefano \& Kamphaus, 2006; Nylund, Asparouhov, \& Muthén, 2007; Nylund, Bellmore, Nishina, \& Graham, 2007), the 5-profile model was selected in favor of the 6-profile model.

Figure 1. The estimated mean of the five profile categories of psychological abuse and neglect 


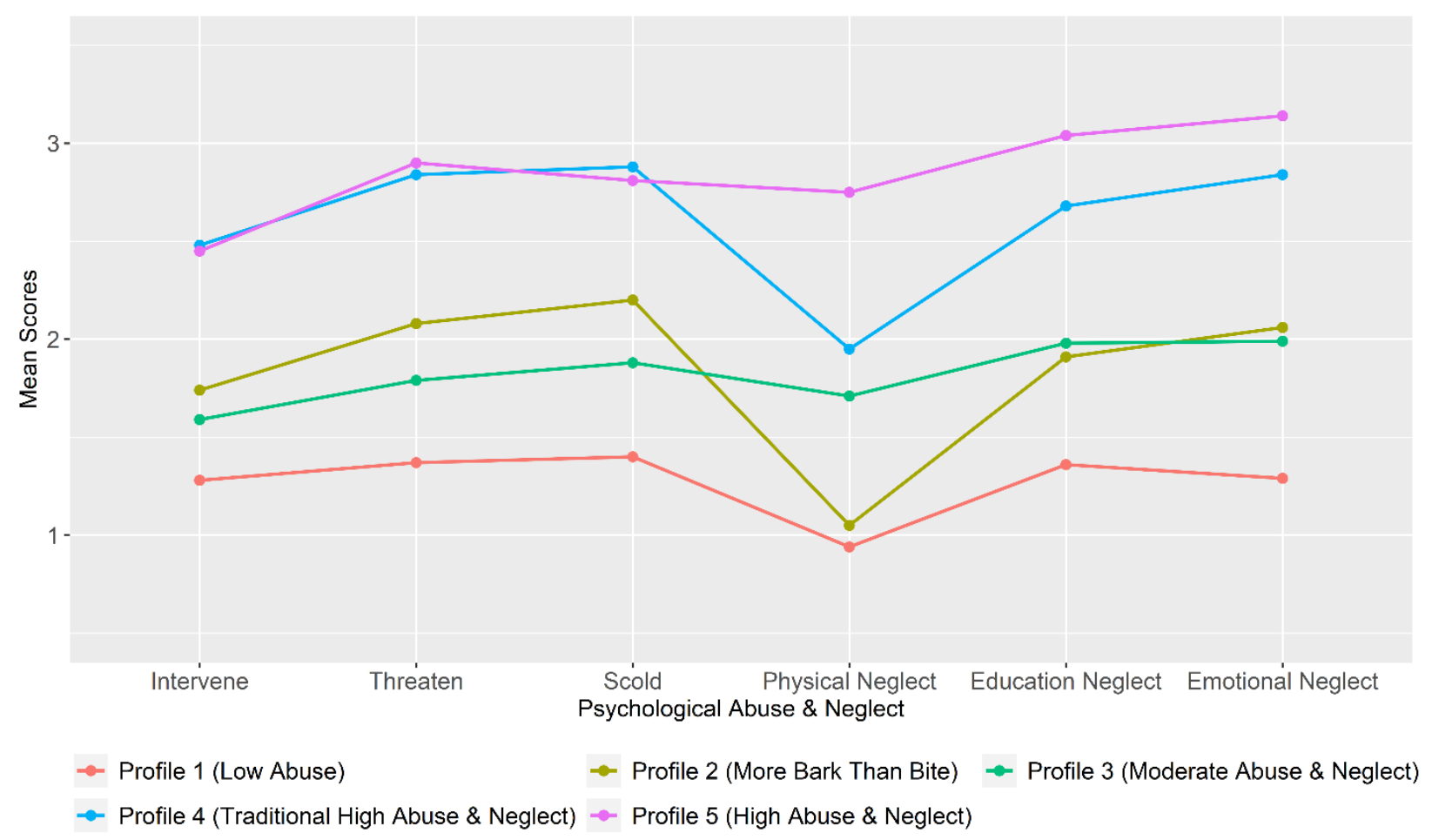

As shown in Figure 1, the five-profile model presents a severity-based gradient of psychological abuse and neglect. Profile 1 was the largest $(n=414,30.76 \%)$, characterized by low severity of psychological abuse and neglect. On average, these students had a warm and relatively free childhood. Their parents paid attention not only to their children's physical condition and school life, but also to their children's emotional changes. Thus, we labeled Profile 1 as the Low Abuse profile. Profile $2(n=260,19.36 \%)$ was comprised of participants that reported moderate psychological abuse and mild neglect. Participants in this profile, on average, reported being scolded for failing to meet the expectations of their parents. However, while their parents were usually externally strict, results indicate that they still cared about their children. Thus, we labeled Profile 2 as the More Bark Than Bite profile. Profile 3 ( $n=360,26.73 \%$ ) reported moderate severity across all measures of psychological abuse and neglect with little to no distinct pattern. Thus, we labeled Profile 3 as the Moderate Abuse \& Neglect profile. Profile 4 $(n=218,16.18 \%)$ displayed a high severity of psychological abuse (on average, serious 
interference, intimidation, and scolding), along with above average level of neglect. Among the three types of neglect, physical neglect was the lowest compared to emotional and education neglect. Thus, we labeled Profile 4 as Traditional High Abuse \& Neglect profile. Finally, Profile $5(n=94,6.98 \%)$ displayed high severity of psychological abuse and neglect across all dimensions. This group exhibited similar levels of psychological abuse in childhood as the Traditional High Abuse \& Neglect profile but deviated in their high report of psychological neglect. Participants in this profile reported their parents exhibiting little care about their performance at school and offering little attention to their emotion and physical health needs. Thus, we labeled Profile 5 as High Abuse \& Neglect profile.

Table 3. Means, standard errors (SE), and mean comparisons of profiling variables across five profiles.

\begin{tabular}{lccccccc}
\hline Profiling Variables & Profile 1 & Profile 2 & Profile 3 & Profile 4 & Profile 5 & $\boldsymbol{F}$ & Post hoc \\
\hline Abuse & & & & & & & \\
$\quad$ Threaten & $1.37 \pm 0.35$ & $2.08 \pm 0.50$ & $1.79 \pm 0.46$ & $2.84 \pm 0.54$ & $2.90 \pm 0.95$ & $402.95^{* * * *}$ & $5 / 4>2>3>1$ \\
$\quad$ Intervene & $1.28 \pm 0.28$ & $1.74 \pm 0.52$ & $1.59 \pm 0.43$ & $2.48 \pm 0.58$ & $2.45 \pm 0.97$ & $265.78^{* * * *}$ & $5 / 4>2>3>1$ \\
$\quad$ Scold & $1.40 \pm 0.39$ & $2.20 \pm 0.64$ & $1.88 \pm 0.53$ & $2.88 \pm 0.65$ & $2.81 \pm 1.00$ & $289.34^{* * *}$ & $5 / 4>2>3>1$ \\
$\quad$ Neglect & & & & & & & \\
$\quad$ Physical Neglect & $0.94 \pm 0.20$ & $1.05 \pm 0.20$ & $1.71 \pm 0.25$ & $1.95 \pm 0.25$ & $2.75 \pm 0.32$ & $1815.52^{* * * *}$ & $5>4>3>2>1$ \\
Education Neglect & $1.36 \pm 0.34$ & $1.91 \pm 0.54$ & $1.98 \pm 0.51$ & $2.68 \pm 0.51$ & $3.04 \pm 0.68$ & $483.24^{* * * *}$ & $5>4>3>2>1$ \\
Emotional Neglect & $1.29 \pm 0.31$ & $2.06 \pm 0.53$ & $1.99 \pm 0.52$ & $2.84 \pm 0.56$ & $3.14 \pm 0.79$ & $391.23^{* * * *}$ & $5 / 4>2 / 3>1$ \\
\hline
\end{tabular}

Note: $N=1307$; ${ }^{* * *} p<0.001$; post-hoc comparisons significant at $p<0.05$; Profile $1=$ Low Abuse, Profile $2=$ More Bark Than Bite, Profile $3=$ Moderate Abuse \& Neglect, Profile $4=$ Traditional High Abuse \& Neglect, Profile $5=$ High Abuse \& Neglect

A one-way multivariate analysis of variance (MANOVA) was run to examine differences between the five profiles among the profiling variables and found significant group variation, $F_{(24,5360)}=145.94, p<0.001 ;$ Pillai's Trace $=1.85 ;$ partial $\eta^{2}=0.46$. Post-hoc comparisons (Table 3) revealed that students in the Low Abuse profile reported significantly lower levels of psychology abuse and neglect, compared with students in other profiles. Students in the More Bark Than Bite profile report greater level of psychological abuse but generally lower neglect 
than students in the Moderate Abuse \& Neglect profile. Students in the Traditional High Abuse \& Neglect profile and the High Abuse \& Neglect profile both reported relatively high levels of psychological abuse and neglect. However, students in the High Abuse \& Neglect profile reported more physical neglect and education neglect than those in the Traditional High Abuse \& Neglect profile.

\subsection{Profile correlates}

Table 4. Multivariate multinomial logistic regression for the identification of profile correlates.

\begin{tabular}{|c|c|c|c|c|c|c|c|c|}
\hline \multirow[b]{2}{*}{ Variables } & \multicolumn{2}{|c|}{ Profile 2} & \multicolumn{2}{|c|}{ Profile 3} & \multicolumn{2}{|c|}{ Profile 4} & \multicolumn{2}{|c|}{ Profile 5} \\
\hline & $\beta$ & $O R$ & $\beta$ & $O R$ & $\beta$ & $O R$ & $\beta$ & OR \\
\hline \multicolumn{9}{|l|}{ Sex } \\
\hline Male & & 1 & & 1 & & 1 & & 1 \\
\hline Female & $-0.67^{* * *}$ & 0.51 & -0.24 & 0.79 & $-0.61^{* * *}$ & 0.54 & $-0.49^{* * *}$ & 0.61 \\
\hline \multicolumn{9}{|l|}{ Home Environment } \\
\hline City & & 1 & & 1 & & 1 & & 1 \\
\hline Rural & -0.10 & 0.91 & 0.12 & 1.12 & 0.09 & 1.09 & $0.55^{*}$ & 1.74 \\
\hline \multicolumn{9}{|l|}{ Father Education } \\
\hline High school & & 1 & & 1 & & 1 & & 1 \\
\hline $\begin{array}{l}\text { Less than Junior } \\
\text { High School }\end{array}$ & $0.80^{* * * *}$ & 2.22 & $0.43^{*}$ & 1.54 & $0.65^{* *}$ & 1.92 & 0.48 & 1.61 \\
\hline Junior high school & 0.04 & 1.14 & -0.18 & 0.84 & 0.17 & 1.18 & -0.01 & 0.99 \\
\hline $\begin{array}{l}\text { Graduate degree } \\
\text { and above }\end{array}$ & -0.20 & 0.82 & $-0.40^{* *}$ & 0.67 & -0.24 & 0.79 & -0.41 & 0.67 \\
\hline \multicolumn{9}{|l|}{ Mother Education } \\
\hline High school & & 1 & & 1 & & 1 & & 1 \\
\hline $\begin{array}{l}\text { Less than Junior } \\
\text { High School }\end{array}$ & 0.07 & 1.07 & 0.07 & 1.07 & 0.27 & 1.31 & 0.49 & 1.63 \\
\hline Junior high school & 0.24 & 1.28 & 0.17 & 1.18 & -0.02 & 0.98 & $-0.51^{*}$ & 0.60 \\
\hline $\begin{array}{l}\text { Graduate degree } \\
\text { and above }\end{array}$ & -0.45 & 0.64 & -0.21 & 0.81 & -0.10 & 0.90 & -0.67 & 0.51 \\
\hline \multicolumn{9}{|l|}{ Family Income } \\
\hline$¥ 6000-8000$ & & 1 & & 1 & & 1 & & 1 \\
\hline$<¥ 4000$ & 0.29 & 1.34 & 0.21 & 1.23 & $0.55^{*}$ & 1.73 & $0.68^{*}$ & 1.97 \\
\hline$¥ 4000-6000$ & 0.14 & 1.15 & 0.17 & 1.19 & -0.08 & 0.92 & -0.13 & 0.88 \\
\hline$¥ 8000-10000$ & 0.02 & 1.02 & -0.15 & 0.86 & 0.00 & 1.00 & -0.19 & 0.82 \\
\hline$¥ 10000+$ & 0.29 & 1.33 & 0.30 & 1.34 & -0.15 & 0.86 & 0.10 & 1.10 \\
\hline
\end{tabular}

Note: ${ }^{* * *} p<0.001,{ }^{* *} p<0.01,{ }^{*} p<0.05$; Profile 1 (Low Abuse) was used as the reference group; italicized variables indicate they were coded as " 0 " and served as the comparison level; Profile 2 $=$ More Bark Than Bite, Profile $3=$ Moderate Abuse \& Neglect, Profile $4=$ Traditional High Abuse \& Neglect, Profile $5=$ High Abuse \& Neglect

The multinomial logistic regression results (see Table 4) indicated that sex, education background of father and mother, and family income significantly related to profile membership. 
As qualities of low abuse and neglect are the most common and representative of normative childhood development, the Low Abuse profile comprised the comparison group across all pairwise logistic regression analyses. Individuals belonging to the Low Abuse profile were generally more likely to be female than all other profiles. Compared with fathers having a high school education, children with fathers having a junior high school education were more likely to experience psychological abuse and neglect. Compared with children in the $¥ 6000-8000$ family income range, children in the $¥ 4000$ or lower family income range were more likely to belong to the Traditional High Neglect Abuse profile and High Abuse \& Neglect profile.

3.3.1. More Bark Than Bite. Students belonging to the More Bark Than Bite profile were more likely to be male and have fathers with a lower level of educational background compared to those in the Low Abuse profile. Based on odds ratios, students with father having below junior high school education background was about 2.22 times more likely to be in the More Bark Than Bite profile compared to individuals in the Low Abuse profile. Indicators of educational background of the mother and total family income were not associated with the profile.

3.3.2. Moderate Abuse and Neglect. Students in the Moderate Abuse \& Neglect profile were about 1.5 times more likely and 1.49 times less likely to have a father with less than Junior High School and college degree or higher education, respectively, compared to their counterparts in the Low Abuse profile. Participant's sex, education background of mother, and family income were not associated with the profile.

3.3.3. Traditional High Abuse and Neglect. Students in the Traditional High Abuse \& Neglect profile were approximately 1.85 times less likely to be female compared to the Low Abuse profile. Students in this profile were also about 1.92 times more likely to have a father with only below junior high school education background and approximately 1.73 times more 
likely to come from a family marked by the lowest ladder of family income, relative to those in the Low Abuse profile. Education background of the mother did not significantly increase the likelihood of being in a more severe profile.

3.3.4. High Abuse and Neglect. Students in the High Abuse \& Neglect profile were approximately 1.64 times more likely to be male and 1.74 times more likely to come from rural residential environments compared to those in the Low Abuse profile. Students in this profile were also approximately 1.67 times less likely to have mothers with junior high school education and approximately 1.97 times more likely to come from the lowest step of the family income ladder. Unlike the prior profiles, education background of the father was not associated with the profile placement.

\subsection{Outcomes}

Table 5. Difference in mean of internet game addiction and cyber-bullying

\begin{tabular}{lcc}
\hline & \multicolumn{2}{c}{ Variables } \\
\cline { 2 - 3 } \multicolumn{1}{c}{ Profiles } & Internet game addiction & Cyber-bullying \\
\hline Profile 1 (Low Abuse and Neglect) & $1.84 \pm 0.05$ & $1.06 \pm 0.02$ \\
Profile 2 (More Bark Than Bite) & $2.17 \pm 0.07$ & $1.09 \pm 0.02$ \\
Profile 3 (Moderate Abuse and Neglect) & $1.96 \pm 0.05$ & $1.16 \pm 0.02$ \\
Profile 4 (Traditional High Abuse and Neglect) & $2.58 \pm 0.06$ & $1.45 \pm 0.05$ \\
Profile 5 (High Abuse and Neglect) & $2.69 \pm 0.11$ & $1.45 \pm 0.09$ \\
Total $\chi^{2}$ & $101.18^{* * *}$ & $79.23^{* * *}$ \\
Post-hoc Comparisons (by Profiles) & $5 / 4>2>3 / 1$ & $5 / 4>3>2 / 1$ \\
\hline
\end{tabular}

Note: ${ }^{* * *} p<0.001$; All post-hoc comparisons significant at $p<0.05$.

Wald chi-square test was adopted to provide comparison among the profile on each of the outcome variables. The results are shown in Table 5.

3.4.1 Internet game addiction. Mean levels of internet game addiction significantly varied across the five profiles $\left(\chi^{2}(4)=101.176, p<0.001\right)$. Specifically, college students who belonged in High Abuse \& Neglect profile reported having higher internet game addiction $(M=$ 
2.69, $S E=0.11)$ than those in the Moderate Abuse \& Neglect profile $\left(M=1.96, S E=0.05 ; \chi^{2}(1)\right.$ $=38.33, p<0.001)$, More Bark Than Bite profile $\left(M=2.17, S E=0.07 ; \chi^{2}(1)=16.29, p<0.001\right)$, and Low Abuse profile $\left(M=1.84, S E=0.05 ; \chi^{2}(1)=51.31, p<0.001\right)$. Similarly, college students in Traditional High Abuse \& Neglect profile report higher internet game addiction $(M=$ $2.59, S E=0.06)$ than those in More Bark Than Bite $\left(\chi^{2}(1)=19.74, p<0.001\right)$, Moderate Abuse $\&$ Neglect $\left(\chi^{2}(1)=60.46, p<0.001\right)$, and Low Abuse profile $\left(\chi^{2}(1)=88.06, p<0.001\right)$. College students who belonged in the More Bark Than Bite profile reported higher internet game addiction $(M=2.59, S E=0.06)$ than those in Moderate Abuse \& Neglect $\left(\chi^{2}(1)=6.83, p=0.009\right)$ or Low Abuse $\left(\chi^{2}(1)=14.39, p<0.001\right)$. However, no significant differences were found in internet game addiction between High Abuse \& Neglect and Traditional High Abuse \& Neglect $\left(\chi^{2}(1)=0.687, p=0.407\right)$ and only a marginal difference was found in internet game addiction between Moderate Abuse \& Neglect and Low Abuse $\left(\chi^{2}(1)=3.45, p=0.063\right)$.

3.4.2 Cyber-bullying. Similarly, college students' mean levels of cyber-bullying also significantly varied across the latent profiles $\left(\chi^{2}(2)=79.23, p<0.001\right)$. Students in the High Abuse \& Neglect profile reported higher cyber-bullying $(M=1.45, S E=0.08)$ than those in the Moderate Abuse \& Neglect profile $\left(M=1.16, S E=0.02 ; \chi^{2}(1)=12.14, p<0.001\right)$, More Bark Than Bite profile $\left(M=1.087, S E=0.02 ; \chi^{2}(1)=19.94, p<0.001\right)$, or Low Abuse profile $(M=$ 1.06, $\left.S E=0.02 ; \chi^{2}(1)=23.74, p<0.001\right)$. Students in the Traditional High Abuse \& Neglect profile exhibited more cyber-bullying $(M=2.58, S E=0.06)$ than the Moderate Abuse \& Neglect profile $\left(\chi^{2}(1)=60.46, p<0.001\right)$, More Bark Than Bite profile $\left(\chi^{2}(1)=49.80, p<0.001\right)$, and Low Abuse profile $\left(\chi^{2}(1)=63.24, p<0.001\right)$. Students in the Moderate Abuse \& Neglect profile reported higher cyber-bullying than those in the Low Abuse profile $\left(\chi^{2}(1)=13.31, p<0.001\right)$. Similar to internet game addiction, those in High Abuse \& Neglect did not significantly differ 
from those in the Traditional High Abuse \& Neglect profile in reported cyber-bullying $\left(\chi^{2}(1)=\right.$ $0.00, p=0.982$ ). Likewise, no significant difference was found in cyber-bullying between the More Bark Than Bite and Low Abuse profiles $\left(\chi^{2}(1)=0.87, p=0.352\right)$.

\section{Discussion}

Utilizing a 'person-centered' approach to statistical analysis, we explored latent child abuse and neglect profiles and further examined the relations between the five profile across key demographic characteristics and outcomes. Our results revealed five latent profiles which mapped characteristics of abuse and neglect: (1) Low Abuse, (2) More Bark Than Bite, (3) Moderate Abuse \& Neglect, (4) Traditional High Abuse \& Neglect, and (5) High Abuse \& Neglect. We also found that those in the Low Abuse profile were more likely to be female and those in profiles characterized by psychological abuse and neglect were more likely to report having fathers with low educational backgrounds. Furthermore, compared to those in other profiles, students belonging to the High Abuse \& Neglect profile had higher levels of internet game addiction and cyber-bullying.

\subsection{Profile categories of child abuse and neglect in college students}

Five distinct profiles emerged whereby one large profile comprised individuals reporting low childhood abuse and neglect which serves as our comparative baseline for normative and secure development. The four remaining profiles of individuals present different patterns of psychological abuse and neglect. The More Bark Than Bite profile represented individuals whose parents' parenting styles are strict, which may subsequently have resulted in greater psychological constraints on the children. As evidenced by the pattern of abuse and neglect for this group, the parents may have elected to encourage their children to meet expectations through the use of threats and scolding. However, it is worth noting that students in this group reported 
rather low levels of physical neglect. It may be such that these parents remain concerned about their child through attention and monitoring of the child's physical health needs, displaying at least some form of parental care. Thus, the parents of students in this profile may be more hold high expectations but may still refrain from allowing such expectations to supersede the priority of the physical well-being of their children.

The Moderate Abuse \& Neglect profile represented individuals who experienced moderate degrees of scolding and all three forms of neglect. While approaching, the scores for use of threats and interventions in childhood were not high enough to warrant being categorized as psychological abuse. For the students in this profile, the primary area of maltreatment stemmed from neglect across domains during their childhood. While moderate on scolding, the lower levels of threat and interventions during childhood may partly be explained by the relatively higher levels of neglect. In other words, because the children were often neglected, the parents of these children may have been less motivated for parental engagement in the first place, inadvertently resulting in the lack of threats and interventions.

The Traditional High Abuse \& Neglect profile represented individuals that experienced serious psychological abuse experience and moderate psychological neglect. Aside from some evident concern for their children's physical needs, the parents of students in this profile appear to provide little attention or care to their children's academic and emotional needs. Lastly, the High Abuse \& Neglect profile, similar to the prior profile, was marked by high levels of psychological abuse. However, unlike the Traditional High Abuse \& Neglect profile, students in this profile also reported high levels of psychological neglect, inclusive of physical neglect. While it is promising that this profile was a small minority of students, it remains concerning that 
these students reported having received little attention or care from their parents across all domains of abuse and neglect during their childhood development.

\subsection{Demographic analysis of different patterns of psychological abuse and neglect}

The multinomial logistic regression suggested that demographic characteristics of sex, parental education background, residential home, and family income were related to profile membership. Females were generally less likely than males to be in profiles characterized by higher abuse and neglect, consistent with prior findings whereby boys were more likely to suffer psychologically from abuse and neglect in China (Zhou, Liang, Cheng, Zheng, \& Liu, 2019). This is, however, notably in contrast to the general trends of studies sampling Western populations (Witt, Brown, Plener, Brahler, \& Fegert, 2017). One possibility of this difference may stem from the traditional Chinese educational model with which many parents follow. That is, because the Chinese culture is traditionally patriarchal, it is common for parents to have more requests for sons and wish them to be composed and responsible. Such doctrine of cultural socialization and education may ultimately lead parents to ignore boys' emotional needs, resulting in boys experiencing more psychological abuse and neglect. Indeed, while it is of no surprise that the differences in culture and social environment Eastern and Western societies will likely yield varying results, the results of this study suggest the need for more attention to be given to the psychological well-being of males residing in China. It is unclear, at least from the results of this study, whether such trends may extend beyond China to neighboring East Asian countries (e.g., South Korea, Japan, etc.). However, given the similarities in cultural roots and more patriarchal doctrine of these East Asian societies, future studies examining the developmental consequences of childhood psychological abuse and neglect may be warranted. 
Results also indicate that one's residential home environment (i.e., rural vs. city) may be related to childhood psychological abuse and neglect. Individuals in the High Abuse \& Neglect profile were more likely to come from rural environments, consistent with the results of a prior study whereby parents in rural areas were more likely to be indifferent to their children's needs (Orsi, Yumaguerrero, Sergi, Pena, \& Shillington, 2018). While it is difficult to say with certainty the underlying reasons of such indifference, one conjecture may be the need for the child to be successful to 'escape' the rural environment. In other words, for many families, leaving the rural environment and entering the urban environments may be deemed a symbol of upward social mobility. To encourage this upward mobility, parents may instill greater pressure on their children to succeed. The evidence for family economic status lends partial credence to this proposition; students in Traditional High Abuse \& Neglect profile and High Abuse \& Neglect profile were more likely to be from families with monthly income below $¥ 4000$. In other words, severe psychological neglect and abuse were more closely related to low family income, consistent with previous research findings (Theron, \& Ungar, 2018; Ajdukovic, Rajter, \& Rezo, 2018), wherein low economic bring individuals a certain degree of life stress (Wißmann, H., Peters, M., \& Müller, S. 2019). Such stressors may cause parents to exhibit greater anxious cognition and poorer coping styles, which in turn, may lead to participation in child abuse (Mclaughlin, 2017).

With regard to parental education background, the father's educational background appeared to be a general characteristic of students' childhood psychological abuse and neglect. Students who reported having fathers with lower educational background (i.e., less than junior high) were more likely to report suffering from childhood psychological abuse and neglect. One reason may be the degree of parental involvement; that is, because fathers with low educational 
backgrounds may hold a more patriarchal and traditional view of gender-based familial roles, fathers with lower education may be less engaged and involved in the parenting process than their more educated counterparts (Chen, Dai, Chen, \& Yang, 2015). Based on our data, it may be such that these fathers often discipline their children in an abusive and neglectful manner. Regarding the mother's education, the mother of students in High Abuse and Neglect profile more likely had with high school education rather than with junior high school education compared to students in the Low Abuse \& Neglect profile. One reason may be that mother with Junior high school education were more likely to be housewives and were able to allocate more time and energy to their children.

In the context of Chinese culture, marked by more traditional patriarchalism, fathers, as the head of the family, have more influence on their children. The results of this study suggest that the government and schools may need to strengthen and broaden the training for lower educated fathers so that they may better participate in their children's social, emotional, and academic lives. Some countries have special parenting programs for parents such as The Incredible Years (Webster-Stratton \& Reid, 2015) and Triple P-Positive Parenting Program (Sanders, 2012), which may be highly effective in changing parenting behaviors (Rotimi \& Dorothy 2019). Recently, China has taken notice of this underlying issue; at the National People's Congress (NPC) and Chinese People's Political Consultative Conference (CPCC) Annual sessions 2020, some delegates to the NPC proposed advances to strengthen education and training for parents. However, because of its recency, the outcomes of such trainings are subject to further future inquiry.

\subsection{The influence of child abuse and neglect on the Internet game addiction and} cyberbullying. 
The five profiles were differentially linked with the outcomes of internet game addiction and cyber-bullying, consistent with prior research (Chen, Lo Camilla, Zhu, Anne, Ling, Patrick, 2018) and our expectations that lower accounts of childhood psychological abuse and neglect would reduce subsequent manifestation of individual online problematic behavior. Indeed, students in profiles marked by high abuse and neglect generally tended to show the most negative outcomes in online behavior. Students in the two most troubled profiles (i.e., Traditional High Abuse \& Neglect and High Abuse \& Neglect) both reported higher levels of internet game addiction and cyberbullying than the other three profiles marked by lesser degrees of abuse and neglect.

Although the psychological neglect scores of the Traditional High Abuse \& Neglect profile were generally lower than that of the High Abuse \& Neglect profile, the students in the two profiles did not differ in their internet game addiction. One conjecture for this may be rooted in childhood psychological abuse scores. The pattern of post-hoc comparison of means (Table 5) generally follow the same top-down direction of abuse scores for the profiles (Figure 1). For students who experienced high levels of childhood psychological abuse, they may have lacked agency or control during key parts of their childhood and early adolescent development. From a Need Fulfillment Theory (Suler, 2014) perspective, one proposition may be that if one's desired needs cannot be met in real life, they may develop a stronger drive to seek temporary diversion in the virtual world. In other words, these students may have relegated themselves to alternative outlets (e.g., online gaming) as distractions and sources to exert the agentic control over their (digital) environment that they otherwise do not have in their real social environment.

Although the High Abuse \& Neglect and Traditional High Abuse \& Neglect profiles were not significantly different in engagement in cyber-bullying, their scores were all significantly 
higher than their lower abuse and neglect counterparts. These findings are in line with prior research evidencing an association between childhood maltreatment and cyber-bullying behavior (Kircaburun et al., 2019; Wang, Jiang, \& Wang, 2019; Wang, Yang, Wang, \& Lei, 2019). Indeed, according to the theory of resource conservation, a harmonious family creates a warm atmosphere for children (Hobfoll, 2001) that can enable parents to properly transfer appropriate social skills and behaviors to their children, thus reducing tendencies to engage in forms of bullying. However, it is also worth noting that the general pattern of means comparison follows the same top-down pattern similarly observed in the progression of profiles for online gaming, but for childhood psychological neglect, rather than abuse. Thus, the findings from this study suggest that childhood psychological abuse may better represent tendencies for online gaming addiction whereas childhood psychological neglect may better reflect tendencies for cyberbullying. However, because our methods in using latent profile analyses inherently take a more exploratory approach, future studies may utilize more confirmatory methods to examine this proposition.

To prevent students from becoming addicted to the online gaming or engaging in cyberbullying, parents' care and love for their children will likely need to be comprehensive, inclusive of reducing psychological abuse and neglect across all relevant domains. Further, parental modeling is likely to also yield significant relation to children's subsequent behaviors. As evidenced by Wang, Yang, et al. (2019), parental moral engagement may transfer to their children, mitigating the negative effects of childhood maltreatment on subsequent cyberbullying behaviors. It is also worth mentioning that given the common co-occurrence of traditional bullying and cyber-bullying (Leemis, Espelage, Basile, Kollar, \& Davis, 2019; Xie, Wei, \& Zhu, 2019), interventions aimed at reducing traditional bullying behavior may have positive spillover 
effects to one's virtual behaviors. Positive parenting behaviors such as parents' physical concern helped college students to establish correct life values in childhood, which can reduce students' bullying behavior.

\section{Conclusion}

This study provides novel evidence about the ways in which childhood psychological abuse and neglect influence important outcomes in problematic online behavior. Findings suggest that there is unobserved heterogeneity amongst Chinese college students with respect to configurations of child psychological abuse and neglect. We provide an initial examination into this by identifying five distinct profiles with which students may be categorized. Compared to females, males generally reported greater levels of psychological abuse and neglect, bringing to attention the possible underlying social ecology of the Chinese culture that may exacerbate the problems of males. Lastly, our examination of online gaming addiction and cyber-bullying provide a novel insight into how the differentiated patterns of abuse and neglect may increase problematic online behaviors. Future studies may benefit from considering how differences in patterns of psychological abuse and neglect may influence additional distinct behavioral negative outcomes. 


\section{References}

Ajdukovic, M., Rajter, M., \& Rezo, I. (2018). Individual and contextual factors for the child abuse potential of Croatian mothers: The role of social support in times of economic hardship. Child Abuse \& Neglect, 78, 60-70. DOI :10.1016/j.chiabu.2018.01.008.

Berzenski, S. R., \& Yates, T. M. (2011). Classes and consequences of multiple maltreatment: A person-centered analysis. Child Maltreatment, 16(4), 250-261. DOI: $10.1177 / 1077559511428353$.

Calvete, E. (2014). Emotional abuse as a predictor of early maladaptive schemas in adolescents: contributions to the development of depressive and social anxiety symptoms. Child Abuse \& Neglect, 38(4), 735-746. DOI: 10.1016/J.CHIABU.2013.10.014.

Cecil, C. A., Viding, E., Barker, E. D., Guiney, J., \& McCrory, E. J. (2014). Double disadvantage: The influence of childhood abuse and community violence exposure on adolescent mental health. Journal of Child Psychology and Psychiatry, 55(7), 839-848. DOI: $10.1111 / \mathrm{JCPP} .12213$.

Chen, Q. Q., Lo, C. K. M., Zhu, Y., Cheung, A., Chan, K. L., \& Ip, P. (2018). Family polyvictimization and cyberbullying among adolescents in a Chinese school sample. Child Abuse \& Neglect, 77, 180-187. DOI: 10.1016/J.CHIABU.2018.01.015.

Chen, Y. L., Dai,Y., Chen, H., Yang, T. (2015). The influence of father's education on middle school students' mental health development. Chinese Journal of School Health, 36(11), 1728-1731. DOI : 10.16835/j.cnki.1000-9817.2015.11.046.

Debowska, A., \& Boduszek, D. (2017). Child abuse and neglect profile and their psychosocial consequences in a large sample of incarcerated males. Child Abuse \& Neglect, 70, 266277. DOI: 10.1016/J.CHIABU.2016.12.003. 
Debowska, A., Willmott, D., Boduszek, D., \& Jones, A. D. (2017). What do we know about child abuse and neglect patterns of co-occurrence? A systematic review of profiling studies and recommendations for future research. Child Abuse \& Neglect, 70, 100-111. DOI: 10.1016/J.CHIABU.2017.06.014.

Deng, Y. L., Pan, C., Tang, Q. P., Yuan, X. H., Xiao, C. G. (2007). Preliminary establishment of Child Psychological Abuse and Neglect Scale. Chinese Journal of Behavioral Medicine and Brain Science, 16(2), 175-177. DOI : 10.16128/j.cnki.1005-3611.2010.04.026.

DiStefano, C., \& Kamphaus, R. W. (2006). Investigating subtypes of child development: A comparison of cluster analysis and latent profile cluster analysis in typology creation. Educational and Psychological Measurement, 66, 778-794. DOI:

$10.1177 / 0013164405284033$.

Elhai, J. D., Rozgonjuk, D., Yildirim, C., Alghraibeh, A. M., \& Alafnan, A. A. (2019). Worry and anger are associated with latent profiles of problematic smartphone use severity among college students. Journal of Affective Disorders, 246, 209-216. DOI: 10.1016/J.JAD.2018.12.047.

Franz, A. O. (2015). Childhood psychological abuse and neglect, personality traits and adulthood relationship quality. Western Carolina University.

Gardner, M. J., Thomas, H. J., \& Erskine, H. E. (2019). The association between five forms of child maltreatment and depressive and anxiety disorders: A systematic review and metaanalysis. Child Abuse \& Neglect, 96, 104082. DOI: 10.1016/J.CHIABU.2019.104082.

Green, J. G., McLaughlin, K. A., Berglund, P. A., Gruber, M. J., Sampson, N. A., Zaslavsky, A. M., \& Kessler, R. C. (2010). Childhood adversities and adult psychiatric disorders in the national comorbidity survey replication I: Associations with first onset of DSM- IV 
disorders. Archives of General Psychiatry, 67(2), 113-123. DOI:

10.1001/ARCHGENPSYCHIATRY.2009.186.

Hobfoll, S. E. (2001). The influence of culture, community, and the nested-self in the stress process: Advancing conservation of resources theory. Applied Psychology, 50(3), 337421. DOI: 10.1111/1464-0597.00062.

Jiang, H.J, Deng, Y.L., \& Pan, C., (2010). Childhood psychological abuse and neglect to vocational college freshmen' mental health: Mediating roles of self-esteem and neuroticism. Chinese Mental Health Journal. 20(1), 262-265.

Jin, T. L., Lu, G. Z., Zhang, L., \& Wu, Y., T., N. (2018). The effect of violent exposure on online aggressive behavior of college students: The role of ruminative responses and internet moral. Acta Psychology Sinica, 39(5), 845-851. DOI:10.3724/SP.J.1041.2018.01051.

Karatekin, C., \& Ahluwalia, R. (2020). Effects of adverse childhood experiences, stress, and social support on the health of college students. Journal of Interpersonal Violence, 35(12), 150-172. DOI: $10.1177 / 0886260516681880$.

Katz, I., Lemish, D., Cohen, R., \& Arden, A. (2019). When parents are inconsistent: Parenting style and adolescents' involvement in cyber-bullying. Journal of Adolescence, 74, 1-12. DOI: 10.1016/J.ADOLESCENCE.2019.04.006.

Kircaburun, K., Jonason, P., Griffiths, M. D., Aslanargun, E., Emirtekin, E., Tosuntaş, Ş. B., \& Billieux, J. (2019). Childhood emotional abuse and cyberbullying perpetration: The role of dark personality traits. 886260519889930. Journal of Interpersonal Violence. DOI:10.1177/0886260519889930. 
Leemis, R. W., Espelage, D. L., Basile, K. C., Kollar, L. M., \& Davis, J. P. (2019). Traditional and cyber bullying and sexual harassment: A longitudinal assessment of risk and protective factors. Aggressive Behavior, 45(2), 181-192. DOI: 10.1002/AB.21808.

Lu, G. Z., Jin, T. L., Ge, J., Ren, X. H., Zhang, L., Zhang, Y. L., \& Jiang, Y. Z., (2019). The effect of violent exposure on online aggressive behavior of college students: A moderated mediation model. Psychological Development and Education, 35(3), 360-367.

DOI:10.16187/j.cnki.issn1001-4918.2019.03.14.

Livazovic, G., \& Ham, E. (2019). Cyberbullying and emotional distress in adolescents: The importance of family, peers and school. Heliyon, 5(6).

DOI :10.1016/j.heliyon.2019.e01992.

Liao, Y., Deng, Y. L. \& Pan, C. (2007). Relationship between psychological abuse experiences and personality characteristics of college students in childhood. Chinese Journal of Clinical Psychology, 2, 647-649.

Liu, W., Liu, F. \& Chen, L. (2018). Impact of psychological abuse on the emotion regulation strategies of children: The mediating effect of personality traits. Journal of Psychological Science, 41(1), 64-70. DOI : 10.16719/j.cnki.1671-6981.20180110.

Maddison, P., Golay, P., \& Muncer, S. (2018). Latent profile analysis of the health of the nation outcome scales: A comparison of Swiss and English profile and exploration of their predictive utility. European Psychiatry, 48(1), 1-5. DOI:

10.1016/J.EURPSY.2017.10.006.

Mertens, Y., Y1lmaz, M., \& Lobbestael, J. (2020). Schema modes mediate the effect of emotional abuse in childhood on the differential expression of personality disorders. Child Abuse \& Neglect, 104, 104445. DOI: 10.1016/J.CHIABU.2020.104445. 
Mcdermott, E. R., Umanataylor, A. J., \& Zeiders, K. H. (2019). Profile of coping with ethnicracial discrimination and Latina/o adolescents' adjustment. Journal of Youth and Adolescence, 48(5), 908-923. DOI: 10.1007/S10964-018-0958-7.

Mclaughlin, M. (2017). Less money, more problems: How changes in disposable income affect child abuse. Child Abuse \& Neglect, 67, 315-321. DOI: 10.1016/J.CHIABU.2017.03.006.

Miller-Perrin, C. L., Perrin, R. D., \& Kocur, J. L. (2009). Parental physical and psychological aggression psychological symptoms in young adults. Child Abuse \& Neglect, 33(1), 1-11. DOI: $10.1016 / \mathrm{J} . \mathrm{CHIABU} .2008 .12 .001$.

Norman, R. E., Byambaa, M., De, R., Butchart, A., Scott, J., \& Vos, T. (2012). The long-term health consequences of child physical abuse, emotional abuse, and neglect: A systematic review and meta-analysis. PLoS Medicine, 9(11), e1001349.

DOI:10.1371/journal.pmed.1001349.

Nylund, K., Asparouhov, T., \& Muthén, B. O. (2007). Deciding on the number of profiles in latent profile analysis and growth mixture modeling: A Monte Carlo simulation study. Structural Equation Modeling, 14(4), 535-569. DOI: 10.1080/10705510701575396.

Nylund, K., Bellmore, A., Nishina, A., \& Graham, S. (2007). Subtypes, severity, and structural stability of peer victimization: What does latent profile analysis say? Child Development, 78(6), 1706-1722. DOI: 10.1111/J.1467-8624.2007.01097.X.

Ogidan, R., \& Ofoha, D. (2019). Assessing the effects of a parenting education program on parental ability to use positive behavior control strategies. South African Journal of Psychology, 49(2), 270-281. DOI: 10.1177/0081246318792397. 
Orsi, R., Yumaguerrero, P., Sergi, K., Pena, A. A., \& Shillington, A. M. (2018). Drug overdose and child abuse across the United States' rural-urban continuum. Child Abuse \& Neglect, 86, 358-367. DOI: 10.1016/J.CHIABU.2018.08.010.

Petrenko, C. L., Friend, A., Garrido, E. F., Taussig, H. N., \& Culhane, S. E. (2016). Does subtype matter? Assessing the effects of abuse on functioning in preadolescent youth in out-of-home care. Child Abuse \&Neglect, 36(9), 633-644. DOI:

10.1016/J.CHIABU.2012.07.001.

Pierce, J., Abbey, A., \& Wegner, R. (2018). Mediators of the association between childhood emotional abuse and young adult men's life satisfaction. Journal of Interpersonal Violence, 33(4), 330-341. DOI: 10.1177/0886260515609584.

Sanders, M. R. (2012). Development, evaluation, and multinational dissemination of the Triple P-Positive Parenting Program. Annual Review of Clinical Psychology, 8(1), 345-379. DOI: 10.1146/ANNUREV-CLINPSY-032511-143104.

Scott, J., Varghese, D., \& McGrath, J. (2010). As the twig is bent, the tree inclines: Adult mental health consequences of childhood adversity. Archives of General Psychiatry, 67(2), 111112. DOI: 10.7556/JAOA.2016.013.

Shaw, M., \& De Jong, M. (2012). Child abuse and neglect: A major public health issue and the role of child and adolescent mental health services. The Psychiatrist Online, 36(9), 321325. DOI: 10.1192/PB.BP.111.037135.

Suler, J. (2005). The online disinhibition effect. International Journal of Applied Psychoanalytic Studies, 2(2), 184-188. DOI: 10.1002/APS.42.

Taillieu, T. L., Brownridge, D. A., Sareen, J., \& Afifi, T. O. (2016). Childhood emotional maltreatment and mental disorders: Results from a nationally representative adult sample 
from the United States. Child Abuse \& Neglect, 59(59), 1-12. DOI:

10.1016/J.CHIABU.2016.07.005.

Theron, L. C., \& Ungar, M. (2018). Limiting the impacts of child abuse and neglect by understanding which supports matter most: A differential impact approach. Child Abuse \& Neglect, 78, 1-3. DOI: 10.1016/J.CHIABU.2018.01.018.

Throuvala, M.A., Janikian, M., Griffiths, M. D., Rennoldson, M, \& Kuss, D.J. (2019). The role of family and personality traits in Internet gaming disorder: A mediation model combining cognitive and attachment perspectives. Journal of Behavioral Addictions, 8 (1), 48-62. DOI: 10.1556/2006.8.2019.05.

Tomoda A., Takiguchi S., Shimada K., Fujisawa T.X. (2017) Structural and Functional Changes of Brain Due to Childhood Maltreatment and Adversity. In: Tsukiura T., Umeda S. (eds) Memory in a Social Context. 251-266. Springer, Tokyo. DOI: 10.1007/978-4-431-565918_14.

Turner, H. A., Shattuck, A., Finkelhor, D., \& Hamby, S. (2016). Poly victimization and youth violence exposure across contexts. Journal of Adolescent Health, 58(2), 208-214.

Wang, G.-F., Jiang, L., Wang, L.-H., Hu, G.-Y., Fang, Y., Yuan, S.-S., ... Su, P.-Y. (2019). Examining childhood maltreatment and school bullying among adolescents a crosssectional study from Anhui province in China. Journal of Interpersonal Violence, 34(5). DOI: $10.1177 / 0886260516647000$.

Wang, X., Yang, J., Wang, P., \& Lei, L. (2019). Childhood maltreatment, moral disengagement, and adolescents' cyber-bullying perpetration: Fathers' and mothers' moral disengagement as moderators. Computers in Human Behavior, 95, 48-57. DOI:

10.1016/j.chb.2019.01.031. 
Wei, H., Zhou, Z. K., Tian, Y., \& Bao., N. (2012). Online game addiction: Effects and mechanisms of flow experience. Psychological Development and Education, 28(6), 6513657. DOI:10.16187/j.cnki.issn1001-4918.2019.03.14.

Webster-Stratton, C., \& Reid, M. J. (2015). The incredible years parents, teachers and children training series: A multifaceted treatment approach for young children with conduct problems. In: Weisz, A. E. \& Kazdin, J. R. (eds.) Evidence-Based Psychotherapies for Children and Adolescents (2nd Ed). New York: Guilford Publications

Wißmann, H., Peters, M., \& Müller, S. (2019). Physical or psychological child abuse and neglect: Experiences, reporting behavior and positions toward mandatory reporting of pediatricians in Berlin, Germany. Child Abuse \& Neglect, 98, 104165. DOI: 10.1016/J.CHIABU.2019.104165.

Witt, A., Brown, R. C., Plener, P. L., Brahler, E., \& Fegert, J. M. (2017). Child abuse in Germany: prevalence rates in the general population. Child and Adolescent Psychiatry and Mental Health, 11(1), 1-9. DOI: 10.1186/S13034-017-0185-0.

Wolfe, D. A., \& McGee, R. A. (1994). Dimensions of child abuse and their relationship to adolescent adjustment. Developmental Psychopathology, 6(1), 165-181. DOI: 10.1017/S0954579400005939.

Xie, J.S., Wei Y. M., Zhu Zhuorong. (2019). Patterns of bullying victimization among adolescents in china: Based on latent profile analysis. Psychological Development and Education, 35(1), 95-102. DOI:10.16187/j.cnki.issn1001-4918.2019.01.11.

Zhao, F., \& Gao, Y. B. (2012). Establishment and reliability and validity test of the scale of adolescent cyberbullying behavior rating. Chinese Mental Health Journal, 26(6), 439$444 \& 383$. 
Zhou, H., Shen, S., Liu, Q., X., \& Zhang, W. (2019). Psychological abuse and neglect are associated with suicidal ideation: A moderated mediation analysis. Journal of Psychological Science, 42(2), 335-342. DOI : 10.16719/j.cnki.1671-6981.20190212.

Zhou, Y., Liang, Y., Cheng, J., Zheng, H., \& Liu, Z. (2019). Child abuse in western China: Demographic differences and associations with mental health. International Journal of Environmental Research and Public Health, 16(19), 3619. DOI:10.3390/ijerph16193619.

Zhou, Z. J., \& Yang. J. (2006). The development of different types of internet addiction scale for undergraduates. Chinese Mental Health Journal, 20(11), 754-757. 